\title{
Care time Delays in Acute Coronary Syndromes with Persistent St Elevation (stem) and the Delaying Factors: Prospective STUDY About 50 Cases in the Cardiology
}

\author{
Momar Dioum $^{1 *}$, Issa KA², Joseph Salvador Mingou², Papa Nguirane Ndiaye², Fatou Aw ${ }^{2}$, Mouhamadou Bamba Ndiaye ${ }^{2}$, Simon Antoine \\ Sarr $^{2}$, Malick Bodian², Aliou Alassane Ngaïdé ${ }^{3}$, Alassane Mbaye ${ }^{3}$, Bouna Diack ${ }^{3}$, Maboury Diao ${ }^{2}$, Abdoul Kane ${ }^{2}$, Serigne AbdouBa $^{2}$. \\ ${ }^{1}$ Cardiology department, Fann Hospital, Faculty of Medicine, Pharmacy and Stomatology, University Cheikh Anta Diop of Dakar (Senegal) \\ ${ }^{2}$ Cardiology department, Teaching Hospital Aristide Le Dantec, Faculty of Medicine, Pharmacy and Stomatology, University Cheikh Anta Diop of \\ Dakar (Senegal) \\ ${ }^{3}$ Cardiology department, Grand Yoff Hospital, Faculty of Medicine, Pharmacy and Stomatology, University Cheikh Anta Diop of Dakar (Senegal) \\ *Corresponding Author: Momar Dioum, Cardiology department, Fann Hospital, Faculty of Medicine, Pharmacy and Stomatology, University \\ Cheikh Anta Diop of Dakar (Senegal); Cheikh Anta DIOP avenue PO Box : 5035.
}

\section{Received date: March 03, 2020; Accepted date: March 06, 2020; Published date: March 15, 2020}

Citation: Momar Dioum., (2020) Care time Delays in Acute Coronary Syndromes with Persistent St Elevation (stem) and the Delaying Factors: Prospective STUDY About 50 Cases in the Cardiology. Journal of Cardiology Research and Reports, 2(1): D0I:10.31579/ 2692-9759/005

Copyright: () 2020 Kenawy A, Mohamad N. Bittar, This is an open access article distributed under the Creative Commons Attribution License, which permits unrestricted use, distribution, and reproduction in any medium, provided the original work is properly cited.

\section{Abstract}

The care of acute coronary syndrome with persistent ST-elevation (STEMI) is a time-trial race: "time is myocardium". The treatment relies on myocardial reperfusion by percutaneous coronary intervention (PCI) or fibrinolysis as promptly as possible. The main objective of this work was to assess the care time delays and the delaying factors during STEMI.

We conducted a prospective, descriptive and analytic study over a 6 months' time period. Were included all the patients recei ved for STEMI. We have studied the care time delays and the delaying factors.

We have compiled 50 patients. The mean age was 58.4 years and the sex-ratio M/F 2.5. The chest pain was typical in 39 patients. The mean time elapsed between the beginning of the pain and the first medical contact was $12 \mathrm{~h} 16 \mathrm{~min}$. Transport (76\%) and self-medication (70\%) were the significant delaying factors found $(\mathrm{p}=0.0001)$. The mean time elapsed between the first medical contact and the electrocardiogram was $9 \mathrm{~h} 57 \mathrm{~min}$. The main factors delaying the diagnosis were the unavailability of the electrocardiogram device and the absence of electrocardiogram prescription $(\mathrm{p}=0.001)$. The mean time elapsed between the electrocardiogram and the admission in the cardiology department was $3 \mathrm{~h} 02 \mathrm{~min}$. The transport was the principal factor lengthening that time delay $(\mathrm{p}=0.0001)$.

Among the patients admitted directly in cardiology department, the mean time delay to perform the ECG was 30 min. The mean time delay of fibrinolysis was $2 \mathrm{~h} 11 \mathrm{~min}$. Streptokinase shortage was the most frequent delaying factor $(\mathrm{p}=0.001)$. The mean time delay between the qualifying ECG and the PCI completion was $2 \mathrm{~h} 42 \mathrm{~min}$. The unavailability of the medical team was the first factor lengthening that time delay $(\mathrm{p}=0.0001)$.

The care time delays were lengthened enough in our context. This testifies to the lack of a codified strategy for STEMI care. It is essential to develop pre-hospital emergency medicine and sensitize the population and healthcare professionals.

Key Words: stemi; delays; pci; fibrinolysis; dakar.

\section{Introduction}

Coronary artery disease has known a regular progression in Senegal with the westernization of the lifestyle and the influence of cardiovascular risk factors. The hospital prevalence of acute coronary syndrome (ACS) went from $7.61 \%$ in 2009 to $10 \%$ in 2016 [1].

Myocardial infarction represents the most severe form of this pathology. The myocardial reperfusion by percutaneous coronary intervention (PCI) or fibrinolysis represent the cornerstone of the treatment [2].
The promptness and efficiency of this reperfusion are the 2 factors that condition the morbidity and mortality rates in the short and long term. The challenge is then to re-canalize the culprit artery and reperfuse the myocardium as soon as possible [3]. The ESC guidelines [4] stipulate that it should be done within 120 minutes maximum following the first medical contact.

There are many steps in STEMI care. Many time delays have been used in the English literature: time-to-first call, symptom onset-to-door, doorto-balloon, time to reperfusion. The European Society of Cardiology has proposed the notion of "first medical contact" (FMC), defined by "the 
place (ambulance or hospital) where, at least in principle, the reperfusion treatment could be initiated".

According to the ESC guidelines of 2017 [4], every patient with STEMI must receive a reperfusion strategy in the 12 first hours following the symptoms. However, in sub-Saharan Africa and especially in Senegal, because of the lack of appropriate organization, the patients attend healthcare beyond the twelfth hour [5].

Thus, our study has focused essentially on the analysis of the admission and care time delays of STEMI admitted in the Cardiology Department of Aristide Le Dantec Teaching Hospital.

The specific objectives were to:

Describe the socio-demographic aspects of the patients who came for STEMI;

Determine the mean time delays of admission, diagnosis, care and the factors lengthening those delays at different levels.

\section{Methodology}

It was a prospective, descriptive and analytic study over 06 months (March 1st to September 30th, 2018). Were included, after informed consent, all the patients received for a STEMI during the study period. We have assessed the time delays at different levels:

- $\quad$ the pain onset and the first medical contact;

- $\quad$ the first medical contact and the first ECG performed; department;

the first ECG performed and the admission in the cardiology

the direct admission in the cardiology department and the completion of ECG;

- $\quad$ the completion of ECG and the beginning of the fibrinolysis; the completion of ECG and the admission in the coronary angiography room.

The factors lengthening these time delays have been analyzed as well as the clinical, electric and angiographic data.

The data were input in EXCEL® software version 2007. The data analysis has been made with SPSS software version 20.

\section{Results}

We have compiled 50 patients. The mean age was 58.4 years $(40-88$ years). The population was made mostly of men with a sex ratio $\mathrm{M} / \mathrm{F}$ of 2.5. Arterial hypertension was in the forefront of the cardiovascular risk factors found with a $46 \%$ prevalence.

The chest pain was typical in 39 patients. The majority of patients $(\mathrm{n}=$ $40 ; 80 \%$ ) was referred to the cardiology department mostly via healthcare facilities (29 patients, or 58\%). Ten patients or $20 \%$ were admitted directly in cardiology. The initial treatment was made of proton pump inhibitor (62\%), analgesic (60\%) and antacid (54\%). Aspirin and Clopidogrel were prescribed respectively to $34 \%$ and $20 \%$ of the patients. More than the half of the patients $(n=29)$ did not know the existence of pre-hospital facilities. Private car and taxi were the most used mean of transport by our patients to attend the cardiology department. The mean time delay between the pain onset and the first medical contact was $12 \mathrm{~h}$ 16 min with extremes of 15 min and 07 days. The 1 st medical contact was the general practitioner in 33 patients; followed by the cardiologist $(\mathrm{n}=$ $8)$ and the nurse $(n=6)$. Transport $(76 \%)$ and self-medication $(70 \%)$ were the most significant lengthening factors found $(\mathrm{p}=0,0001)$. The mean time delaybetween the first medical contact and the ECG completion was
9 h $57 \mathrm{~min}$ ( $5 \mathrm{~min}$ and 07 days). The main factors delaying the diagnosis were the unavailability of the ECG device and the absence of ECG prescription $(\mathrm{p}=0.001)$. The mean time delay between the ECG completion and the admission in the cardiology department was $3 \mathrm{~h} 02$ min with extremes of $30 \mathrm{~min}$ and $48 \mathrm{~h}$. Transport was the main factor lengthening that time-delay ( $p=0.0001$ ) followed by financial issues. Among the patients directly admitted in cardiology, the mean time delay to perform ECG was $30 \mathrm{~min}(02-120 \mathrm{~min})$. The slowness of the paramedical personnel was the main delaying factor $(64 \%)$ with a significant $\mathrm{p}$ of 0.0001 . Thirty-five (35) patients were admitted on time for the fibrinolysis. Seventeen patients or $34 \%$ has benefit from fibrinolysis. The mean time delay for fibrinolysis was $2 \mathrm{~h} 11 \mathrm{~min}$ with extremes of $40 \mathrm{~min}$ and $7 \mathrm{~h}$. A shortage of streptokinase was the most frequent delaying factor $(\mathrm{p}=0,001)$. A primary PCI was performed in 23 patients with a mean time delay of $2 \mathrm{~h} 42 \mathrm{~min}$ with extremes of $30 \mathrm{~min}$ and $10 \mathrm{~h}$ between the qualifying electrocardiogram and the transfer to the coronary angiography room. The unavailability of the medical or paramedical team was the factor lengthening that time delay $(\mathrm{p}=0.0001)$.

\section{Discussion}

In our series, we have noticed a male predominance (72\%). This result is comparable to the literature in Africa (INTERHEART Africa) [6] and in the West [7]. This difference between the two genders could be explained by the protective effect of estrogen in women before menopause. Our patients were one-decade younger compared to western series $[8,7,9]$. In Africa, especially Saharan, patients attend generally peripheral healthcare facilities before being referred to cardiology. Yameogo [5] in Burkina has found 3 facilities attended before admission in cardiology. Thus, the general practitioner was the firstt medical contact in 33 patients (64\%). Only eight patients have been consulted by a cardiologist (16\%). This could be explained by the health pyramid, the proximity of the districts and the low cost of care.

Private car and taxi are the means of transport mostly used by our patients (54\%) to attend the cardiology department. It is the general rule in Africa [5, 10]. The pre-hospital facilities are exceptionally requested. This strategy differs from European countries, where the emergency rapid respond units are very requested [11]. However, the high cost of these services and their availability could be an obstacle for their use. The means of transport used by the patients compete to lengthen the admission time delays. As found in the other African studies [5, 12], the mean time delay between the pain onset and the consultation was $12 \mathrm{~h} 16 \mathrm{~min}$. The delaying factors were transport and self-medication. The mean time delay between the first medical contact and the completion of electrocardiogram was $9 \mathrm{~h} 57 \mathrm{~min}$ for out-care patients. It was $39.77 \mathrm{~min}$ for patients admitted directly in cardiology. This is far from ESC 2017 recommendations that require a time delay of $10 \mathrm{~min}$ [4] to perform a 12-lead ECG when a patient is cared for chest pain. The factors responsible for this long time delay were the ignorance of the medical contact, the impossibility to perform ECG and the paramedical slowness. Out-care patients diagnosed were admitted after 3 hours because of transport or financial issues, or ECG interpretation. The mean time delay to start the fibrinolysis was long (130.53 min) compared to YAMEOGO (34 min) [5], and Hadj (122 min) [12]. The shortage of streptokinase was the delaying factor mostly noticed. Thus, the mean time delay $(2.7 \mathrm{~h})$ to perform primary PCI was better than Hadj's (6h 28min) [12]. The unavailability of the medical team was the most noticed lengthening factor. 


\section{Parameters Delays}

\begin{tabular}{|c|c|}
\hline $\begin{array}{c}\text { Pain and the first medical contact } \\
\text { First medical contact and the } \\
\text { electrocardiogram }\end{array}$ & $12 \mathrm{~h} 16 \mathrm{~min}$ \\
\hline $\begin{array}{c}\text { Qualifying ECG and the admission in the } \\
\text { cardiology }\end{array}$ & $3 \mathrm{~h} 02 \mathrm{~min}$ \\
\hline $\begin{array}{c}\text { Admitted directly in cardiology delay to } \\
\text { perform the ECG }\end{array}$ & $30 \mathrm{~min}$ \\
\hline $\begin{array}{c}\text { Qualifying ECG of fibrinolysis } \\
\text { Qualifying ECG and the PCl }\end{array}$ & $2 \mathrm{~h} 11 \mathrm{~min}$ \\
\hline
\end{tabular}

Table. I: Different delays

\begin{tabular}{|c|c|}
\hline FACTORS EXTENDING DELAYS & P \\
\hline Transport & 0,0001 \\
\hline Self-medication & 0,0001 \\
\hline $\begin{array}{c}\text { Unavailability of the electrocardiogram device and the absence of } \\
\text { electrocardiogram prescription }\end{array}$ & 0,0001 \\
\hline Pechnical difficulties to realize the electrocardiogram & 0,0001 \\
\hline Streptokinase shortage & 0,0001 \\
\hline Unavailability of the medical team & 0,001 \\
\hline
\end{tabular}

Table. II Main factors extending delays

\section{Conclusion}

The care time delays were quite lengthened in our context. This shows the lack of codified care strategy of STEMI. It is essential to develop pre-hospital emergency medicine and sensitize the population and healthcare professionals.

\section{References}

1. Dioum M, Mbaye A, Ngaide A et al. (2016). Prevalence and Management of Acute Coronary Syndrome with Persistent STSegment Elevation in Cardiology Unit of General Hospital of Grand Yoff in Dakar (Experience a Single Center). J Cardiovasc Dis Diagn, $4: 6$.

2. Keeley EC, Hillis LD. (2007). Primary PCI for myocardial infarction with ST-segment elevation. N Engl J Med, 356:4754.
3. Kushner FG, Hand M, Smith Jr SC et al. (2009). Focused Updates: ACC/AHA Guidelines for the management of patients with ST Elevation myocardial infarction (Updating the 2004 Guideline and 2007 Focused Update) and ACC/AHA/SCAI Guidelines on Percutaneous Coronary Intervention (Updating the 2005 Guideline and 2007 Focused Update): A Report of the American College of Cardiology Foundation/American Heart Association Task Force on Practice Guidelines. J Am Coll Cardiol, 54:2205-2224.

4. Borja I, Stefan J, Stefan A et al. (2017). ESC Guidelines for the management of acute myocardial infarction in patients presenting with ST-segment elevation. The Task Force for the management of acute myocardial infarction in patients presenting with ST-segment elevation of the European Society of Cardiology (ESC). Eur Heart J, 00:1-66.

5. Yameogo NV, Samadoulougou A, Millogo G et al. (2012). Délais de prise en charge des syndromes coronariens aigus avec sus-décalage du segment ST à Ouagadougou et facteurs 
associés à un allongement de ces délais : étude transversale à propos de 43 cas colligés au CHU-Yalgado Ouédraogo. Pan Afr Med J, $13: 90$

6. Stone GW, Brodie BR, Griffin JJ et al. (1998). Prospective, Multicenter Study of the Safety and Feasibility of Primary Stenting in acute Myocardial Infarction: In-Hospital and 30Day Results of the PAMI Stent Pilot Trial. J Am Coll Cardiol, 31:23-30.

7. Hanssen M, Cottin Y, Khalife K et al. (2010). French Registry on Acute ST-elevation and non ST-elevation Myocardial Infarction, FAST-MI 2010 Heart 2012;98:699-705.

8. Marcaggi X, Bitar G, Ferrier N. (2005). Angioplastie coronaire dans un centre de petit volume. Ann Cardiol Angéiol(Paris), 54:317-321.
9. Chan PS, Patel MR, Klein LW et al. (2011). Appropriateness of Percutaneous Coronary Intervention. JAMA, 306:53-61.

10. Ba SA. (2016). Epidémiologie de la coronaropathie en Afrique. Congrès APPAC, 8-10

11. Hurlimann C, Arveiler D, Romier-Borgnat S et al. (1998). Evaluation des délais de prise en charge de l'infarctus du myocarde: résultats d'une enquête en Alsace. Arch Mal Cour, 91(7):873-878.

12. Hadj A. Le (2016). syndrome coronarien aigu avec susdécalage persistant du segment ST (STEMI): données du registre ReSCUS
This work is licensed under Creative Commons Attribution 4.0 License

\section{To Submit Your Article Click Here: Submit Article}

DOI:10.31579/crr.2020/005

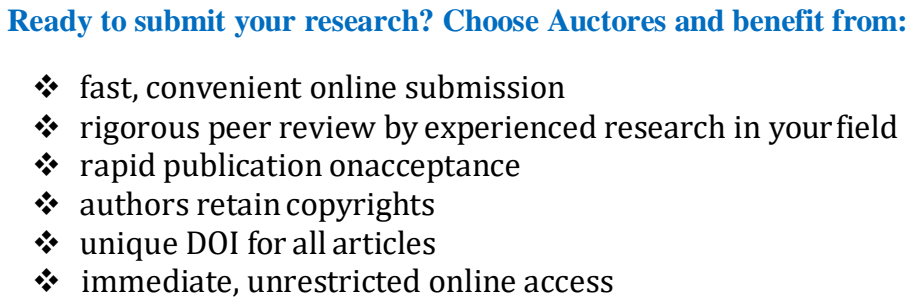

At Auctores, research is always inprogress.

Learn more www.auctoresonline.org/journals/cardiology-researchand-reports 